\title{
High-Risk Behaviors Related to Intentional and Unintentional Harm in Adolescents of Zahedan, Iran
}

\author{
Alireza Ansari-Moghaddam ${ }^{1}$; Nour-Mohammad Bakhshani ${ }^{2}$; Mohsen Hoseinbore ${ }^{3}$; Fariba \\ Shahhraki Sanavi ${ }^{1, *}$ \\ ${ }_{2}^{1}$ Health Promotion Research Center, Zahedan University of Medical Sciences, Zahedan, IR Iran \\ ${ }_{3}^{2}$ Children and Adolescents Health Research Center, Zahedan University of Medical Sciences, Zahedan, IR Iran \\ 3 Iranshahr University of Medical Sciences, Iranshahr, IR Iran \\ ${ }^{*}$ Corresponding author: Fariba Shahhraki Sanavi, Health Promotion Research Center, Zahedan University of Medical Sciences, Zahedan, IR Iran. Tel: +98-9153412916, E-mail: shah- \\ raki_sunavi@yahoo.com \\ Received: May 20, 2014; Revised: September 30, 2014; Accepted: October 6, 2014
}

\begin{abstract}
Background: Adolescence and youth are life-threatening stages of development when a range of unsafe behaviors can harmfully affect a person's health and their social and educational performance.

Objectives: The present study aimed to determine the incidence and prevalence of high-risk behaviors related to intentional and unintentional harm in adolescents of Zahedan(Iran).

Patients and Methods: This cross-sectional study included 1000 randomly selected male and female high school students of Zahedan, Iran. The Persian version of High Risk Behavior Questionnaire and Goldberg's 28-item General Health Questionnaire were used to collect data. Descriptive statistics (frequency and percentage) was used to analyze data.

Results: The most prevalent behaviors were not wearing seat belt (48\%), riding a motorcycle without a helmet (42.3\%) and involvement in physical conflicts (38.7\%). Both the incidence and prevalence of the studied behaviors were higher in boys than girls. Moreover, greater prevalence of behaviors related to intentional and unintentional harm was observed in subjects with a drug abusing friend or family member.

Conclusions: The incidence and prevalence of high-risk behaviors in the studied population were slightly lower compared to several other parts of the country and some other countries. Nevertheless, since the rates and trend are alarming, sectoral and intersectoral cooperation is indispensable to the implementation of preventive interventions at different levels of society. Such efforts would obviously require the help of experts in various fields and necessitate the assessment of sociocultural features of the population.
\end{abstract}

Keywords: Adolescence; Hazardous Behaviors; Epidemiology

\section{Background}

Adolescence is a multidimensional stage of human development accompanied by rapid and dramatic physical, mental, cognitive and social changes, which has significant effects on health-related behaviors (1). Despite improvements in impulse control following natural growth, emotional, cognitive and behavioral processes remain immature during adolescence. This may lead to reckless behaviors, emotional reactions and ignorance of possible negative outcomes (2). Adolescence and youth are critical stages of development when a variety of risky behaviors can negatively affect a person's health and their social and educational performances (3).

On the other hand, considering health behaviors in adolescence is of utmost importance, since several causes of mortality in this period depend on adolescents' behaviors. Furthermore, this period of life is the crucial transition from being controlled by parents to independency and self-determination (4). Accordingly, epidemiologic evidences have shown that involvement in risky behaviors reaches its peak in youth. A risky behavior is any behavior or reaction that can potentially harm biological and psychological aspects of growth (5). Escobar-Chaves et al. defined risky behaviors and adventurousness as tendency to get involved in behaviors threatening either physical or mental health (6).

About a half of the world's population is currently younger than 25 years (7). Importantly, the Center for Disease Control and Prevention (CDC) reported intentional and unintentional injuries as the main cause of mortality among 15 to 24 -year-olds. While most (73\%) deaths occurred in car accidents, others were the result of a wide range of incidents such as use of firearms, explosions, falls, bicycle accidents, poisoning and collisions with an object (8). Similar to the reports from the

Copyright (C) 2015, Zahedan University of Medical Sciences. This is an open-access article distributed under the terms of the Creative Commons Attribution-NonCommercial 4.0 International License (http://creativecommons.org/licenses/by-nc/4.0/) which permits copy and redistribute the material just in noncommercial usages, provided the original work is properly cited. 
USA, Japan and Hong Kong, the Iranian Legal Medicine Organization has also identified automobile accident injuries as the leading cause of death in individuals younger than 25 years $(9,10)$.

Nevertheless, the CDC reported the rate of suicide among adolescents as 7-9\% in 2004 (11). Moreover, most recent statistics showed that the prevalence of self-harm and suicidal thoughts were $13 \%$ and $26 \%$, respectively (12). In the USA suicidal behaviors were recognized as the third cause of death among 15-24-year-old population (13). Iran has a young population structure. As adolescents are the most susceptible age group to high-risk behaviors, increasing prevalence of such behaviors among Iranian adolescents and youth has turned into a major social issue (14). Therefore, evaluating the incidence and priorities of adolescent health-risk behaviors can reveal valuable information and enable health policy makers to design education and prevention plans, which truly target the real needs and challenges faced by this group of population $(15,16)$.

\section{Objectives}

The current study aimed to identify the frequency of high-risk behaviors related to intentional and unintentional harm in adolescents of Zahedan (Iran).

\section{Patients and Methods}

The study population of this cross-sectional study was all male and female students attending high school in Zahedan (Sistan and Baluchestan Province, Iran). Then, a multistage cluster random sampling method was used to include a sample size of 1000 students for this survey. Basically, schools are classified into two categories in Zahedan. Accordingly, at first all high schools in study area were listed. Secondly, two girls' and two boys' schools from the first region and three girls' and three boys' schools from the second region of the study region were randomly selected based on the proportion of high schools in the two regions of the city. Finally, three or four classes (each class as one cluster) were randomly selected from each school according to the population of students at each selected school. The Goldberg and Hillier's 28-item General Health Questionnaire (GHQ-28) (17) and High Risk Behaviors Questionnaire (HRBQ) (8) were used to collect data. The GHQ-28 has been developed to screen nonpsychotic mental disorders in both treatment centers and the society. The 28 items of the questionnaire are arranged in four seven-item subscales (somatic symptoms, anxiety/insomnia, social dysfunction and depression). To calculate an individual's total score, the scores of all four subscales were summed up (18). The Cronbach's alpha of GHQ-28 has been reported as $0.78-0.93$. The split-half reliability of the questionnaire has also been suggested as 0.83-0.90 (8). The RBS has been designed based on a similar questionnaire by the US CDC and has acceptable validity and reliability
(19). Furthermore, self-reported information was used to measure incidence and prevalence of high-risk behaviors. Indeed, committing intentional and unintentional harm in the year before the study for the first time was considered as incidence. In comparison, performance of such a behavior for at least one day in their life was classified as prevalence.

The questionnaires were distributed among 1000 selected subjects who were assured about the anonymity and confidentiality of data. Overall, 16 questionnaires were excluded as they were not returned or were unusable (conflict in selected options or main items left unanswered). Finally, data of 984 students were analyzed by descriptive statistical indices (mean, frequency and percentage) using SPSS 15 for Windows (SPSS Inc., Chicago, IL, USA).

\section{Results}

A total of 984 high school students from Zahedan were included in the present study. Most subjects (68.3\%) were 14-16 years old and remaining (31.7\%) aged $17-19$ years. According to Tables 1 and 2, the prevalence and incidence of physical conflicts were $38.7 \%$ and $23.7 \%$, respectively. Moreover, $23.5 \%$ of the participants had been wounded during such conflicts and $15.5 \%$ of them had their first injuries during the year before the study. Experience of carrying cold weapons and firearms was reported by $18.6 \%$ and $10.9 \%$ of the participants, respectively. Moreover, $10.2 \%$ and $5.9 \%$ of the teenagers had carried cold weapons and firearms during the past year. Suicide attempts were made by $14.4 \%$ of the participants and $7.7 \%$ during the past year. The prevalence and incidence of thoughts of death and wish for death were $27.3 \%$ and $17.6 \%$, respectively. Generally, $35.2 \%, 42.3 \%$ and $48.0 \%$ of the participants had experienced driving without a driver's license, riding a motorcycle without a helmet and not wearing seat belt, respectively. In $25.5 \%, 24.8 \%$ and $29.9 \%$ of the studied subjects, the aforementioned experiences occurred during the last year.

As the tables show, high-risk behaviors related to intentional and unintentional harm were more prevalent among the students whose family members or friends were drug abusers. In addition, the same adolescents had lower levels of general health. Finally, 18.0\% of participants had at least once absconded from school and 7.6\% had experience of running away from home. The incidence and prevalence of such behaviors were higher in boys than girls.

\section{Discussion}

The findings of the present study indicated that not wearing the car seat belt, riding motorcycles without a helmet and involvement in physical conflicts were the commonest behaviors related to intentional and unintentional harm in adolescents. Furthermore, such behaviors had higher prevalence and incidence in boys than girls. 


\begin{tabular}{|c|c|c|c|c|c|c|c|c|c|c|c|}
\hline Variable & $\begin{array}{c}\text { Escape } \\
\text { From } \\
\text { Home }\end{array}$ & $\begin{array}{c}\text { Escape } \\
\text { From } \\
\text { School }\end{array}$ & $\begin{array}{c}\text { Not } \\
\text { Wearing } \\
\text { Seat Belt }\end{array}$ & $\begin{array}{c}\text { Riding a Motor- } \\
\text { cycle Without a } \\
\text { Helmet }\end{array}$ & $\begin{array}{c}\text { Driving With- } \\
\text { out a Driver's } \\
\text { License }\end{array}$ & $\begin{array}{c}\text { Thought of } \\
\text { Death and } \\
\text { Wish for Death }\end{array}$ & $\begin{array}{c}\text { Suicide } \\
\text { Attempt }\end{array}$ & $\begin{array}{l}\text { Carrying } \\
\text { Firearms }\end{array}$ & $\begin{array}{c}\text { Carry- } \\
\text { ing Cold } \\
\text { Weapons }\end{array}$ & $\begin{array}{l}\text { Physical } \\
\text { Conflicts }\end{array}$ & $\begin{array}{l}\text { Injury in } \\
\text { Physical } \\
\text { Conflicts }\end{array}$ \\
\hline \multicolumn{12}{|l|}{ Gender } \\
\hline Female & 6.9 & 8.9 & 46.5 & 37.4 & 20.0 & 31.7 & 18.9 & 9.6 & 29.1 & 19 & 19 \\
\hline Male & 8 & 24.9 & 49.0 & 45.6 & 46.6 & 24.2 & 11.3 & 11.8 & 45.6 & 26.7 & 26.7 \\
\hline \multicolumn{12}{|l|}{ Age, y } \\
\hline $14-16$ & 6.9 & 17.6 & 48.6 & 44.3 & 37.4 & 29.0 & 14.7 & 10.8 & 40.4 & 22.5 & 22.5 \\
\hline $17-19$ & 10.3 & 19.3 & 48.8 & 40.3 & 31.2 & 15.5 & 13.4 & 12.8 & 36.1 & 26.6 & 26.6 \\
\hline \multicolumn{12}{|c|}{$\begin{array}{l}\text { History of drug } \\
\text { abuse in the } \\
\text { family }\end{array}$} \\
\hline Yes & 15.4 & 36.8 & 70.5 & 57.3 & 50.5 & 59.4 & 44.9 & 30.6 & 71.1 & 51.5 & 51.5 \\
\hline No & 15.5 & 24.7 & 45.3 & 40.6 & 33.8 & 23.7 & 10.8 & 8.8 & 35.3 & 20.3 & 20.3 \\
\hline \multicolumn{12}{|c|}{$\begin{array}{l}\text { History of drug } \\
\text { abuse among } \\
\text { friends }\end{array}$} \\
\hline Yes & 24.8 & 40.0 & 64.3 & 54.7 & 59.3 & 48.3 & 33.1 & 31.7 & 71.1 & 50.8 & 50.8 \\
\hline No & 4.7 & 14.5 & 46.4 & 41 & 32.4 & 24.6 & 11.5 & 7.8 & 34.6 & 19.5 & 19.5 \\
\hline \multicolumn{12}{|c|}{ General health } \\
\hline Normal & 3.5 & 14.5 & 44.4 & 38.4 & 32.8 & 15.5 & 4.8 & 7.2 & 32.0 & 17.0 & 17.0 \\
\hline Abnormal & 12.5 & 23.7 & 51.0 & 48.0 & 38.0 & 44.6 & 26.4 & 15.2 & 47.9 & 33.0 & 33.0 \\
\hline Total & 7.6 & 18.1 & 48.0 & 42.3 & 35.4 & 27.3 & 14.4 & 10.9 & 18.6 & 38.7 & 23.5 \\
\hline
\end{tabular}

${ }^{\mathrm{a}}$ Data are presented as \%.

Table 2. The Incidence of Behaviors Related to Intentional and Unintentional Harm in the Studied Adolescents ${ }^{a}$

\begin{tabular}{|c|c|c|c|c|c|c|c|c|c|c|c|}
\hline Variable & $\begin{array}{l}\text { Escape } \\
\text { From } \\
\text { Home }\end{array}$ & $\begin{array}{c}\text { Escape } \\
\text { From } \\
\text { School }\end{array}$ & $\begin{array}{c}\text { Not } \\
\text { Wearing } \\
\text { Seat belt }\end{array}$ & $\begin{array}{c}\text { Riding a Motor- } \\
\text { cycle Without a } \\
\text { Helmet }\end{array}$ & $\begin{array}{l}\text { Driving With- } \\
\text { out a Driver's } \\
\text { License }\end{array}$ & $\begin{array}{c}\text { Thought of } \\
\text { Death and } \\
\text { Wish for Death }\end{array}$ & $\begin{array}{c}\text { Suicide } \\
\text { Attempt }\end{array}$ & $\begin{array}{l}\text { Carrying } \\
\text { Firearms }\end{array}$ & $\begin{array}{c}\text { Carry- } \\
\text { ing Cold } \\
\text { Weapons }\end{array}$ & $\begin{array}{l}\text { Physical } \\
\text { Conflicts }\end{array}$ & $\begin{array}{l}\text { Injury in } \\
\text { Physical } \\
\text { Conflicts }\end{array}$ \\
\hline \multicolumn{12}{|l|}{ Gender } \\
\hline Female & 2.0 & 2.8 & 29.4 & 17.2 & 13.8 & 21.9 & 8.9 & 3.3 & 7.3 & 17.6 & 13.0 \\
\hline Male & 3.8 & 16.6 & 30.3 & 29.8 & 34.1 & 14.5 & 6.9 & 8.0 & 12.3 & 28.1 & 17.2 \\
\hline \multicolumn{12}{|l|}{ Age, $y$} \\
\hline $14-16$ & 3.3 & 10.8 & 29.8 & 24.8 & 27.5 & 18.2 & 7.1 & 6.4 & 12.7 & 24.5 & 15.1 \\
\hline $17-19$ & 2.7 & 10.8 & 29.9 & 24 & 21.7 & 16.6 & 9.2 & 4.9 & 5.2 & 22.3 & 16.4 \\
\hline \multicolumn{12}{|c|}{$\begin{array}{l}\text { History of drug } \\
\text { abuse in the } \\
\text { family }\end{array}$} \\
\hline Yes & 12.4 & 22.1 & 50.5 & 40.4 & 42.1 & 36.5 & 28.6 & 16.3 & 18.4 & 42.3 & 37.1 \\
\hline No & 1.8 & 8.9 & 27.4 & 22.9 & 23.7 & 15.3 & 5.3 & 4.8 & 9.3 & 21.8 & 13.0 \\
\hline \multicolumn{12}{|c|}{$\begin{array}{l}\text { History of drug } \\
\text { abuse among } \\
\text { friends }\end{array}$} \\
\hline Yes & 12.4 & 22.5 & 35.7 & 33.0 & 43.2 & 29.2 & 20.7 & 18.3 & 23.1 & 40.8 & 27.5 \\
\hline No & 1.4 & 8.8 & 29.6 & 23.6 & 23.1 & 16.1 & 5.7 & 4.2 & 8.3 & 21.5 & 13.9 \\
\hline \multicolumn{12}{|c|}{ General health } \\
\hline Normal & 1.1 & 9.3 & 25.3 & 21.5 & 21.2 & 8.3 & 2.6 & 4.3 & 7.1 & 17.1 & 10.3 \\
\hline Abnormal & 4.9 & 13.2 & 33.4 & 29.7 & 28.3 & 31.2 & 14.3 & 7.3 & 13.9 & 30.9 & 23.0 \\
\hline Total & 3.1 & 10.8 & 29.9 & 24.8 & 25.5 & 17.6 & 7.7 & 5.9 & 10.2 & 23.7 & 15.5 \\
\hline
\end{tabular}

a Data are presented as \%. 
Ansari-Moghaddam A et al.

In fact, the two genders had different patterns of highrisk behaviors. The most prevalent behaviors in boys were not wearing seat belt, driving without a driver's license, involvement in physical conflicts and riding motorcycles without a helmet. In comparison, not wearing seat belt, riding motorcycles without a helmet and thoughts of death and wish for death had the greatest prevalence in girls. Moreover, driving without a driver's license, involvement in physical conflicts and riding motorcycles without a helmet had the highest incidence in boys. In girls, on the other hand, riding motorcycles without a helmet, thoughts and/or wishes of death and not wearing seat belt had the greatest incidence in girls. Nevertheless, the two age groups were not different for the incidence or prevalence of high-risk behaviors. In both age groups, not wearing seat belt, riding motorcycles without a helmet and involvement in physical conflicts had the highest prevalence and incidence.

Behaviors related to intentional and unintentional harm were generally commoner in families with drug abusers. Involvement in physical conflicts was the most prevalent behavior in adolescents from these families. Meanwhile, subjects with drug abusing friends reported not wearing seat belt and involvement in physical conflicts more than others. About a half of the subjects with higher prevalence of not wearing seat belt and involvement in physical conflicts had abnormal general health. From incidence point of view, abnormal general health was also found in roughly one-third of adolescents with experiences of not wearing seat belt, thought of death and wish for death, involvement in physical conflicts, riding motorcycles without a helmet and driving without a driver's license. The prevalence of escape from school was three times higher in boys than girls. However, the incidence of this behavior was almost similar in the two genders. Escape from school and home was more prevalent among the 17-19 and 14-16 year-old subjects, respectively. Both the incidence and prevalence of escape from home and school were greater in adolescents with a drug abusing friend or family member.

A study in 2004-2005 in Zahedan (8) showed that $42.6 \%$ of high school students rode a motorcycle during the 12-month period before the study, from whom, $78.0 \%$ had never used a helmet. During the same period, $39.2 \%$ of the participants had not worn seat belt and $49.3 \%$ of them had at least once driven a car without a driver's license. Furthermore, about $22.1 \%$ of the studied adolescents had carried a weapon (a gun or knife) for at least one day in their lifetime. In the year before the study, 6.7\%, 53.3\% and $41.8 \%$ of the students had at least once carried a gun, gotten involved in physical conflicts and fights, and gotten injured, respectively. Suicide attempts and several days of depression were also reported by $19.6 \%$ and $69.0 \%$ of the participants. Feeling insecure prevented $14.2 \%$ of the students from attending school for at least one day. A total of $40.9 \%$ of the subjects had escaped from school and $4.0 \%$ had left home without permission during the year be- fore the research (8). A comparison between the findings of the present study and those of the above-mentioned research suggests that despite general reductions in the prevalence and incidence of high-risk behaviors among adolescents in Zahedan, not wearing seat belt and escape from home and school have become commoner.

In a study on Icelandic high school students, $16.2 \%$ of girls and $25.6 \%$ of boys ( $21.2 \%$ of the whole sample) did not regularly wear seat belt. Furthermore, $21.3 \%$ of the participants ( $8.5 \%$ of girls and $33.0 \%$ of boys) carried guns. Suicidal thoughts, plans and attempts were also reported by $23.7 \%, 18.8 \%$ and $7.7 \%$ of the subjects. Suicide attempts were more prevalent in girls than boys (11.3\%vs. $4.4 \%)(20)$. Not only suicide attempt, but also not wearing seat belt was more prevalent in the current study compared to the Icelandic students. The latter can be a result of better culture building in Iceland. On the other hand, the greater prevalence of carrying a gun among the Icelandic students can be justified by higher accessibility of guns in Iceland.

Grarmaroudi et al. (9) reported the prevalence of intentional harm and not wearing seat belt in high school students of Tehran (Iran) as $41.5 \%$ and $88.6 \%$, respectively. The lower prevalence in the current study may suggest the higher prevalence of such behaviors in metropolises (9). Similar to the present findings, a study reported injuries due to riding motorcycles without helmet and driving motor vehicles while being drunk in $41.7 \%$ and $14.6 \%$ of American adolescents, respectively. It also showed the prevalence of carrying guns and knives as $15.2 \%$ and that of involvement in physical conflicts as $6.3 \%$. Moreover, $22.4 \%$ of the participants had felt depressed or desperate at least once every two weeks (21).

In 2001, the World Health Organization announced selfharm as the cause of about 814000 deaths worldwide (11). There is some evidence that self-harm is 10 times more likely to be prevalent in adolescents with suicidal thoughts than others (12). Furthermore, similar to the present study, international data indicates that suicide attempts are generally more prevalent in girls than boys (7). Previous studies found stressful events such as tension in the family due to parents' drug abuse as a risk factor of suicide in adolescents (2). The higher incidence and prevalence of suicide attempts in subjects with a drug abusing friend or family member in the current study was consistent with available data. On the other hand, Kirchner et al. reported that self-harm behaviors in the US and Europe initiate at the age of 16 (12), which are in line with the findings of the present research.

A study by Dainis (22) revealed that $85.0 \%$ of the students in Lynchburg (USA) never wore a helmet while bicycling and $5.0 \%$ did not fasten their seat belt. About $26.0 \%$ of the participants had an experience of sitting in a car with a drunk driver and $11.0 \%$ had driven a car after drinking alcoholic beverages. During the 30 days before the study, firearms and cold weapons had been carried by $4.0 \%$ and $18.0 \%$ of the subjects, respectively. In addition, dur- 
ing the year prior to the study, 7.0\% of participants had been threatened or injured by cold weapons. In the same period, 22.0\% of the adolescents had gotten involved in physical conflicts and 5.0\% required medical procedures. About one fourth (24.0\%) of the students reported a constant feeling of depression for two weeks or more. The prevalence of suicide plans, intention for suicide and suicide attempts were $7.0 \%, 4.0 \%$ and $11.0 \%$, respectively (22). Comparisons showed that not wearing seat belt and carrying firearms were less prevalent in students of Lynchburg than our participants. However, not wearing helmet while bicycling, carrying weapons and suicide attempts were more prevalent in the students of Lynchburg.

On the whole, evaluation of high-risk behaviors is crucial as it can affect the adolescents' life, health and psychosocial development (23). In addition, since such behaviors may make adolescents face irreparable damage whose correction requires a great deal of time and money, preventive measures and behavior change interventions at individual and social levels can be the most appropriate techniques to decrease the prevalence of such behaviors in the society (24). Finally, we observed a greater prevalence of high-risk behaviors in adolescents with drug abusing friends or family members. Besides public preventive programs, educational interventions targeting individuals and groups at higher risk have to be designed and implemented. There is a need for larger studies to assess the reasons for increased incidence of high-risk behaviors.

\section{Acknowledgements}

We are sincerely grateful to the Education Organization and the personnel of high schools in Zahedan who assisted us in data collection. We would like to appreciate the Education Office and all personnel of Zahedan high schools for their contribution in data collection.

\section{Authors' Contributions}

The overall implementation of study design, data management and analysis and manuscript preparation were the results of joint efforts by multiple individuals listed as coauthors of this paper. All authors made extensive contribution into the review and finalization of this manuscript. All the authors read and approved the final manuscript.

\section{Funding/Support}

Deputy of research, Education Office of Sistan and Baluchestan Province, Iran supported this study.

\section{References}

1. Reyna VF, Rivers SE. Current Theories of Risk and Rational Decision Making. Dev Rev. 2008;28(1):1-11.

2. Dawes MA, Mathias CW, Richard DM, Hill-Kapturczak N, Dough- erty DM. Adolescent Suicidal Behavior and Substance Use: Developmental Mechanisms. Subst Abuse. 2008;2:13-28.

3. Stansfield KH, Kirstein CL. Neurochemical effects of cocaine in adolescence compared to adulthood. Brain Res Dev Brain Res. 2005;159(2):119-25.

4. Bakhshani NM, Birashk B, Bolhary J. Sexual advice and say, No, in critical situations to prevent AIDS in youth. .Tehran: Tehran Institute of Psychiatry; 2003.

5. Jessor R, Turbin MS, Costa FM. Risk and Protection in Successful Outcomes Among Disadvantaged Adolescents. Appl Dev Sci. 1998;2(4):194-208.

6. Escobar-Chaves SL, Tortolero SR, Markham CM, Low BJ, Eitel P, Thickstun P. Impact of the media on adolescent sexual attitudes and behaviors. Pediatrics. 2005;116(1):303-26.

7. Maharaj RG, Nunes P, Renwick S. Health risk behaviours among adolescents in the English-speaking Caribbean: a review. Child Adolesc Psychiatry Ment Health. 2009;3(1):10.

8. Bakhshani NM, Lashkaripour K, Bakhshani S, Hoseinbore M. Prevalence of risk behaviors related to intentional and unintentional injuries among adolescent high school students of Sistan and Balouchestan, Southeast of Iran. Tabib Shargh. 2007;9(3):199-208.

9. Grarmaroudi GR, Makarem J, Alavi S. Health related risk behaviors among high school students In Tehran, Iran. Payesh. 2010;9(1):13-9.

10. Baheiraei A, Hamzehgardeshi Z, Mohammadi MR, Nedjat S. Violence-related behaviors and self-inflicted injuries among 1518 year old Iranian adolescents. Indian Pediatr. 2011;48(12):984-5.

11. Pompili M, Serafini G, Innamorati M, Dominici G, Ferracuti S, Kotzalidis GD, et al. Suicidal behavior and alcohol abuse. Int J Environ Res Public Health. 2010;7(4):1392-431.

12. Kirchner T, Ferrer L, Forns M, Zanini D. Self-harm behavior and suicidal ideation among high school students. Gender differences and relationship with coping strategies. Actas Esp Psiquiatr. 2011;39(4):226-35.

13. Anderson RN, Smith BL. Deaths: leading causes for 2001. Natl Vital Stat Rep. 2003;52(9):1-85.

14. Khajehkazemi R, Osooli M, Sajadi L, Karamouzian M, Sedaghat A, Fahimfar N, et al. HIV prevalence and risk behaviours among people who inject drugs in Iran: the 2010 National Surveillance Survey. Sex Transm Infect. 2013;89 Suppl 3:iii29-32.

15. Smith TME. A Comparison of Health Risk Behaviors Among College Students Enrolled in a Required Personal Health Course vs. Enrolled in an Elective Personal Health Course.: Virginia Polytechnic Institute and State University; 2004.

16. Carroll L, Perez MM, Taylor RM. The Evidence for Violence Prevention Across the Lifespan and Around the World: Workshop Summary.Washington (DC): National Academies Press; 2014.

17. Goldberg DP, Hillier VF. A scaled version of the General Health Questionnaire. Psychol Med.1979;9(1):139-45.

18. Ebrahimi A, Barekatain M, Bornamanesh A, Najafi MR, Salehzadeh M, Maracy MR. Psychometric properties and validation of Persian version of quality of life in epilepsy inventory (QOLIE-89).J Res Med Sci. 2013;18(11):990-4.

19. Ebrahimi A, Afshar H, Doost HT, Mousavi SG, Moolavi H. Attitude scale and general health questionnaire subscales predict depression? J Res Med Sci. 2012;17(1):40-4.

20. Grunbaum JA, Kann L, Kinchen SA, Williams B, Ross JG, Lowry R, et al. Youth risk behavior surveillance--United States, 2001. MMWR Surveill Summ. 2002;51(4):1-62.

21. Babington LM, Kelley BR, Patsdaughter CA. Risk behaviors of Dominican adolescents in their homeland and in the United States. J Pediatr Health Care. 2007;21(6):372-80.

22. Dainis A. 2012 Youth Survey Report. 2014. Available from: www.cdc. gov/HealthyYouth/yrbs/index.htm.

23. Steinberg L. A Social Neuroscience Perspective on Adolescent Risk-Taking. Dev Rev. 2008;28(1):78-106.

24. Hurd N, Zimmerman M. Natural mentors, mental health, and risk behaviors: a longitudinal analysis of African American adolescents transitioning into adulthood. Am J Community Psychol. 2010;46(1-2):36-48. 